\title{
Premigration social adversity and autism spectrum disorder
}

Natacha Augereau, Ines Lagdas, Solenn Kermarrec, Ludovic Gicquel, Virginie Martin, Jean Xavier, David Cohen, Michel Bouvet, Anne-Catherine Rolland and Sylvie Tordjman

\section{Background}

Several studies suggest significant relationships between migration and autism spectrum disorder (ASD) but there are discrepant results. Given that no studies to date have included a pathological control group, the specificity of the results in ASD can be questioned.

\section{Aims \\ To compare the migration experience (premigration, migratory trip, postmigration) in ASD and non-ASD pathological control groups, and study the relationships between migration and autism severity.}

\section{Method}

Parents' and grandparents' migrant status was compared in 30 prepubertal boys with ASD and 30 prepubertal boys without ASD but with language disorders, using a questionnaire including Human Development Index (HDI)/Inequality-adjusted Human Development Index (IHDI) of native countries. Autism severity was assessed using the Child Autism Rating Scale, Autism Diagnostic Observation Schedule and Autism Diagnostic Interview-Revised scales.

\section{Results}

The parents' and grandparents' migrant status frequency did not differ between ASD and control groups and was not associated with autism severity. The HDI/IHDI values of native countries were significantly lower for parents and grandparents of children with ASD compared with the controls, especially for paternal grandparents. Furthermore, HDI/IDHI levels from the paternal line (father and especially paternal grandparents) were significantly negatively correlated with autism severity, particularly for social interaction impairments.

\section{Conclusions}

In this study, parents' and/or grandparents' migrant status did not discriminate ASD and pathological control groups and did not contribute either to autism severity. However, the HDI/IHDI results suggest that social adversity-related stress experienced in native countries, especially by paternal grandparents, is potentially a traumatic experience that may play a role in ASD development. A 'premigration theory of autism' is then proposed.

\section{Keywords}

Autism spectrum disorder (ASD); migration; human development index (HDI/IHDI); social adversity; premigration stress.

\section{Copyright and usage}

(c) The Author(s) 2020. This is an Open Access article, distributed under the terms of the Creative Commons AttributionNonCommercial-NoDerivatives licence (http://creativecommons.org/licenses/by-nc-nd/4.0/), which permits non-commercial re-use, distribution, and reproduction in any medium, provided the original work is unaltered and is properly cited. The written permission of Cambridge University Press must be obtained for commercial re-use or in order to create a derivative work.
Autism is a multifactorial disorder involving environmental and genetic factors. ${ }^{1}$ Some environmental risk factors have been reported for autism spectrum disorder (ASD), such as parental migration. ${ }^{2-5}$ Several authors have developed a 'migration theory of autism' ${ }^{2-8}$ questioning the role of migration among environmental vulnerability factors for autism even if migration has not been associated with any specific mental or psychological conditions. The updated literature review on migration and autism indicates that studies on this topic are relatively new. Wing ${ }^{9}$ was the first to study potential links between migration and autism. Then, studies compared the frequencies of migrant parents for children with autism and children in the general population, and the frequencies of children with autism in migrant populations and non-migrant populations. Studies were mostly based on the general population registry. The migration experience itself was rarely studied. The main studies on migration and autism are presented in Table 1 . They show that paternal migration was not always studied. ${ }^{6,11,13,16}$ Furthermore, Magnusson et al ${ }^{7}$ observed a higher risk of autism when parents have migrated, especially when they came from countries associated with a low Human Development Index (HDI).

The HDI is a measure of average achievement in three key dimensions of human development: a long and healthy life (health), being knowledgeable (education) and having a decent standard of living (living standards). ${ }^{17}$ The HDI values vary from 0 (very low HDI) to 1 (very high HDI) and each country is associated with an HDI value. The health dimension is assessed by life expectancy at birth. The education dimension is measured by mean of years of schooling for adults aged 25 years and older and expected years of schooling for children entering school. The standard of living dimension is measured by gross national income per capita. There is also the IHDI (Inequality-adjusted HDI) that combines a country's average achievements in health, education and income with how those achievements are distributed among the country's population by 'discounting' each dimension's average value according to its level of inequality. HDI/IHDI values of native countries can be used as indicators of premigration social adversity (the lower HDI/IHDI is, the higher social adversity experience is). Based on the Magnusson study, ${ }^{7}$ it can be hypothesised that lower HDI/IHDI values might be associated with autism.

As shown in Table 1, there are some discrepant results regarding relationships between ASD and migration and no study has compared an ASD group with a non-ASD pathological control group. Consequently, it remains unclear whether the association between migration and ASD is specific or not to autism. Given that most environmental risk factors for ASD are also risk factors for other neurodevelopmental disorders, this needs to be investigated. ${ }^{5}$ Also, it remains unclear whether the association between migration and ASD is indirectly related to variables that co-occur often with migration (for example trauma, social adversity). The main objective of the present study was to explore the relationships between migration and autism by comparing ASD and non-ASD pathological control groups and studying the associations between migration and autism 
Gillberg et al, $1987^{10} \quad$ Epidemiological study based on a Swedish population registry comparing migrant parents' frequency between the autism and control groups

Gillberg et al, 1995

Gillberg \& Gillberg, $1996^{12}$

Study of autism prevalence in children born in Sweden from mothers born in Uganda

Epidemiological study based on a Swedish population registry comparing migrant parents' frequency between the autism and control groups

Lauritsen et al, $2005^{13}$

Epidemiological study based on a Danish population registry comparing migrant parents' frequency between the autism and control groups

Keen et al, $2010^{\circ}$

Retrospective study based on English population registry comparing ASD prevalence according to mother's native country and her ethnic group

Barnevik-Olsson et al, $2010^{14}$ Epidemiological study based on a Swedish population registry focusing on autism prevalence in Somali background population compared with non-Somali population

Magnusson et al, 2012$$
\text { population }
$$

pese-control study based on population registry (Stockholm youth cohort) comparing migrant parents' frequency between the autism and control groups

Schieve et $\mathrm{al}, 2012^{15}$

Study based on an American population registry comparing ASD prevalence in US-born non-Hispanic children and US-born Hispanic children

Becerra et al, 2014 $\quad$ Epidemiological study based on an American population registry comparing autism prevalence according to mother's native country and ethnicity
35 children with autism (20 living in urban area and 15 living in rural area) compared to 42886 age-matched children in the general population from the same region

3 children with autism born in Sweden from mothers born in Uganda

55 children with autism for 78106 children (genera population)

818 children with autism born in Denmark from a cohort of 943664 children in general population

428 children with autism

250 children with autism (232 non-Somali and 18 Somali) 113391 children in general population (111 555 nonSomali and 1836 Somali)

3918 children with autism (2269 high functioning and 1649 low functioning) for 589114 children in general population

US-born non-Hispanic children $(n=37,265)$ and US-born Hispanic children $(n=4,690)$

7540 children with autism from a cohort of 1626354 children in general population matched on age
Six of the $20(30 \%)$ urban children with autism had migrant parents whereas none $(0 \%)$ of the rural children with autism had migrant parents; the frequency of migrant parents was significantly lower in ASD rural children compared to typically developing controls $(0 \%$ V. $25.7 \%, P<0.001)$; no significant difference was observed regarding the frequency of migrant parents between the urban ASD and typically developing control groups. Autism prevalence in children born in Sweden from mothers born in Ugand (15\%) compared with prevalence of autism in general population (0.08\%) $27 \%$ children with autism compared with $26.2 \%$ children in general population have migrant parents (non-significant)

Relative risk of ASD evaluated at 1.42 when mothers born outside European continent compared with mother born in Denmark

Relative risk of autism higher for children whose mothers born in the Caribbean (OR=10.01, 95\% Cl 5.53-18.1), in Asia (OR=3.97, 95\% Cl 2.01-7.84), in Africa (OR=7.92, 95\% Cl 5.39-11.6)

Autism prevalence higher in Somali background children compared with nonSomali children $(P<0.001)$

Relative risk of low-functioning autism higher in migrant population when the two parents were migrant $(\mathrm{OR}=1.5,95 \% \mathrm{Cl} 1.3-1.7)$, mainly if parents came from countries associated with low Human Development Index

Hispanic children with two US-born parents had a higher ASD prevalence than non-Hispanic children $(2.39 \%$ v. $1.19 \%, P>0.05)$ or Hispanic children with two foreign-born parents $(2.39 \%$ v. $0.31 \%, P<0.05)$

Higher relative risk of autism when mothers are Asian and born in Philippines $(\mathrm{OR}=1.23,95 \% \mathrm{Cl} 1.08-1.40)$ or in Vietnam $(\mathrm{OR}=1.45,95 \% \mathrm{Cl} 1.24-1.70)$ compared with white mothers born in USA 
severity. A second objective was to better understand the role of the migration experience (i.e. premigration, migratory trip or postmigration) as a possible factor of vulnerability for the development of ASD.

\section{Method}

\section{Participants}

Participants were individuals with ASD $(n=30)$ who were compared with a pathological non-ASD control group $(n=30)$ matched for age, gender and puberty. The two groups did not differ significantly with respect to age, gender and pubertal status. The ASD group included 30 male prepubertal children with autism (mean age: 11.4 years; s.d. = 2.1 years; range: $7.9-15.7$ years) recruited from French day care centres. Based on direct clinical observation of the child by two independent child psychiatrists, a diagnosis of autism was made for the ASD group according to the criteria of the American classification (DSM-5), ${ }^{18}$ the World Health Organization classification (ICD10) ${ }^{19}$ and the French classification (CFTMEA). ${ }^{20}$ This diagnosis was confirmed using Autism Diagnostic Interview-Revised (ADI$\mathrm{R})^{21}$ and Autism Diagnostic Observation Schedule (ADOS) ${ }^{22}$ ratings. Indeed, combining information from multiple sources, based on clinical psychiatric judgement and the administration of the ADI-R completed by the ADOS, is a more reliable method. ${ }^{23}$

The pathological non-ASD control group included 30 male prepubertal children (mean age 10.7; s.d. $=2.1$ years; range: $8.5-15.5$ years) with spoken-language disorders (such as speech with phonological deficits, semantics deficits, or morphology and syntax deficits) who had at least a language examination with a speech therapist in French out-patient care centres. In particular, these children, despite their verbal language problems, used verbal language for reciprocal social communication and did not show abnormal non-verbal communication. Furthermore, these children did not show autistic behaviours such as deficits in social communication (social withdrawal, etc.) and stereotyped behaviours or interests including insistence on sameness. Based on direct clinical observation of the child by two independent child psychiatrists, a diagnosis of autism was excluded according to DSM-5, ICD-10 and CFTMEA criteria.

Written informed consent was obtained from all parents after explaining the study and its procedure to the parents and their children. The protocol was approved by the ethics committee of the University Hospital of Rennes.

\section{Behavioural and cognitive assessments}

The ADI-R is an extensive semi-structured parental interview validated to assess current autistic behavioural impairments and past autistic behavioural impairments that were the most abnormal during the 4- to 5-year-old period. The ADI-R algorithm is based on the 4- to 5-year-old period of life. The ADOS is a direct observation of the individual in a standardised semi-structured situation of play. The ADOS Module 1, administered to individuals with no or limited speech, was used in this study. The ADI-R and ADOS were administered by two trained professionals (one child psychiatrist and one psychologist) certified in these scales administration. Also, the Child Autism Rating Scale (CARS) was used with the ADOS in the same standardised situation of play. The ADI-R, ADOS and CARS scales allowed the assessment of autism severity in major domains of autistic impairments: reciprocal social interaction, communication, repetitive behaviours and stereotyped patterns. In addition, the CARS allowed us to get an overall rating of autism severity corresponding to the CARS Total score. The higher the scores are, the more severe are autistic impairments. On the basis of the ADI-R and ADOS algorithms, children with autism $(n=30)$ displayed severe scores of autistic behavioural impairments in reciprocal social interaction (mean score: 25.00, s.d. $=4.47$ for the ADI-R with a cut-off of 10; mean score: 9.43, s.d. $=2.71$ for the ADOS with a cut-off of 7), communication (mean score: 12.06 , s.d. $=2.43$ for the ADI-R non-verbal communication domain with a cut-off of 7 ; mean score: 5.79 , s.d. $=2.08$ for the ADOS communication domain with a cut-off of 4 ), and repetitive or stereotyped patterns (mean score: 6.20 , s.d. $=2.00$ for the ADI-R with a cut-off of 3; mean score: 3.29 , s.d. $=1.24$ for the ADOS with no cut-off). The mean score for the Total social communication domain of the ADOS was 15.21 (s.d. = 4.22) with a cut-off of 12. Finally, the CARS Total mean score was 40.84 (s.d. $=5.84$ ) (a total score above 30 corresponds to a diagnosis of mild and moderate autism and a total score above 37.5 corresponds to a diagnosis of severe autism).

Cognitive functioning was assessed in the ASD group by one psychologist using Raven's Color Progressive Matrices (R-CPM) which is a short $(20 \mathrm{~min})$ non-verbal intelligence test validated for young children from 5 years old and individuals with intellectual disability. ${ }^{24}$ The R-CPM is an instrument of particular interest for children with ASD with intellectual disability. ${ }^{25,26}$ Children in the ASD group were all cognitively impaired except for 3 children:

16 boys had intellectual disability (Raven class 4 or 5); 2 boys showed average intellectual functioning (Raven class 3 ); 1 boy showed higher intellectual functioning (Raven class 2); and cognitive assessment was impossible for 11 children in the ASD group (difficulties with understanding instructions or too high excitation interfering with administration).

\section{Migration status assessment}

The parents' and grandparents' migration status was assessed using an original questionnaire, developed specifically by the authors, and entitled FEVA (Factors of Environmental Vulnerability for Autism). The FEVA questionnaire was administered during semistructured parental interviews and included questions on parents and grandparents place of birth allowing HDI/IHDI values associated with native countries to be obtained. Also, based on prior studies the following information was collected: date of family immigration to France (grandparents, parents and/or children), language spoken at home, degree of urbanisation in parental living conditions, links with the native country and community, acculturation process, presence of family members in the host country and quality of relationships with these family members, perception of immigration (especially, as a stressful experience), and motivation for leaving native countries. ${ }^{6,7,10,13,15,27}$

\section{Statistical analyses}

The relationships between qualitative variables were analysed using $\chi^{2}$-tests or Fisher tests. The comparison of quantitative variables between ASD and control groups was performed using $t$-tests and ANOVA. When there was a directional hypothesis (lower HDI/ IHDI values might be associated with autism), one-tailed $t$-test of significance was used. To balance type I and type II errors in the statistical analysis of behavioural autistic domains, a hierarchical strategy was used. ${ }^{28}$ First, the total behavioural domains were examined. If there was a significant result for an overall domain, then a further level of analysis occurred on the subscores included in the domain. Correlations between quantitative variables were studied using Bravais-Pearson correlation analyses. Statistical analyses were performed using SAS software (SAS Institute, Cary, NC, USA). The qualitative analysis was conducted using the grounded theory approach based on categorisation and theories concerning cultural, social or psychological phenomenon developed from qualitative empirical data. ${ }^{29}$ 
Table 2 Comparison of the mean values (s.d.) on the Human Development Index (HDI) and Inequality-adjusted Human Development Index (IHDI) for native countries in the autism spectrum disorder (ASD) and control groups

\begin{tabular}{|c|c|c|c|c|c|}
\hline HDI/IHDI & $\begin{array}{l}\text { ASD group } \\
\quad(n=30)\end{array}$ & $\begin{array}{c}\text { Control } \\
\text { group }(n=30)\end{array}$ & d.f. & $t$-value & $P$ \\
\hline \multicolumn{6}{|l|}{$\mathrm{HDI}$} \\
\hline Mother & $0.82(0.14)$ & $0.86(0.09)$ & 58.0 & 1.69 & 0.045 \\
\hline Father & $0.83(0.14)$ & $0.88(0.07)$ & 40.8 & 1.71 & 0.045 \\
\hline Maternal grandmother & $0.82(0.14)$ & $0.87(0.09)$ & 58.0 & 1.63 & 0.050 \\
\hline Maternal grandfather & $0.81(0.14)$ & $0.87(0.09)$ & 51.1 & 1.90 & 0.030 \\
\hline Paternal grandmother & $0.81(0.15)$ & $0.87(0.07)$ & 41.0 & 2.08 & 0.020 \\
\hline Paternal grandmother & $0.81(0.15)$ & $0.87(0.07)$ & 40.6 & 2.11 & 0.020 \\
\hline \multicolumn{6}{|l|}{ IHDI } \\
\hline Mother & $0.71(0.17)$ & $0.78(0.12)$ & 58.0 & 1.67 & 0.050 \\
\hline Father & $0.73(0.17)$ & $0.79(0.09)$ & 42.8 & 1.65 & 0.050 \\
\hline Maternal grandmother & $0.71(0.17)$ & $0.77(0.12)$ & 58.0 & 1.62 & 0.055 \\
\hline Maternal grandfather & $0.70(0.17)$ & $0.77(0.12)$ & 58.0 & 1.90 & 0.030 \\
\hline Paternal grandmother & $0.71(0.18)$ & $0.78(0.09)$ & 42.7 & 2.01 & 0.025 \\
\hline Paternal grandmother & $0.70(0.18)$ & $0.78(0.09)$ & 42.6 & 2.20 & 0.015 \\
\hline
\end{tabular}

\section{Results}

\section{Qualitative results}

\section{Migration experience}

The reasons for leaving native countries were similar for both groups and included fleeing harsh living conditions (reflecting high social adversity), gaining access to graduate studies, employment or high-quality healthcare, and/or joining the partner or other family members already living in France. Both groups reported stress associated with migration when arriving in France concerning administrative problems, memories of hazardous trip, social insecurity and poverty. Also, stress could continue after arriving in France because of administrative problems or family distance when some members were still living in native countries. All migrant families in the ASD and control groups had family members in France before arriving in France (siblings, uncles/ aunts, cousins). Good relationships with these family members were reported and parents indicated speaking their mother tongue with them daily. Finally, most of the families for both groups affirmed a preference for staying in France rather than going back to the native country. It is noteworthy that regarding these qualitative data, no differences were found between the ASD and the pathological non-ASD control groups (in the migrant subgroups).

\section{Language spoken at home}

In the migrant ASD group, parents declared that they tried to speak exclusively the host country language to their child because they were afraid that the child might get 'confused'. However, the native and host country languages were sometimes used alternately at home with the children in the ASD group. In contrast, migrant parents spoke their mother tongue to the children in the control group.

\section{Relationships between migration and autism}

Frequencies of immigrant parents (ASD: $n=10 / 30$ families with seven fathers and nine mothers; non-ASD: $n=5 / 30$ families with three fathers and three mothers) or immigrant grandparents (ASD: 13/60 families with eight paternal grandparents and five maternal grandparents; non-ASD: 6/60 families with three paternal grandparents and three maternal grandparents) did not differ significantly between the ASD and the non-ASD control groups, and this result was found regardless of the way in which the migration status was analysed (at least one parent migrant, only fathers migrant, only mothers migrant, etc.). It is noteworthy that in the control group there was no paternal grandparents who migrated with the father or maternal grandparents who migrated with the mother.

Also, for the nine migrant mothers in the ASD group, two migrations occurred during the perinatal period (one migration 3 months after delivery and one migration in the third trimester of pregnancy); for the three migrant mothers in the control group, no migration occurred during the perinatal period. Except for one child in the ASD group and one child in the control group, all children were born in France. Migrant parents in the ASD group came from the following countries: Algeria, Cameroon, Democratic Republic of Congo, Gabon, Guinea, Haiti, India, Morocco, Sierra Leone and Vietnam. Migrant parents in the control group came from the following countries: Dominican Republic, England, Guinea, Haiti and Turkey.

In the ASD group, no significant relationship was found between parental migration status and autism severity assessed using the ADOS, ADI-R or CARS scales. It is noteworthy that no significant relationship was observed, in particular, between parental migration status and severity of verbal and non-verbal communication impairments assessed on the ADOS, ADI-R as well as CARS scales. Also, no significant relationship was observed between the language spoken at home to the child (same language as at school or other language) and autism diagnosis when the ASD and control groups were compared or when this comparison focused on the migrant ASD and control subgroups.

\section{Comparison of the migration parental experience in the ASD and control groups}

No significant difference was found between the ASD and control groups regarding relationships with the native community (in France or in the native country) and observance of cultural and/ or religious rituals, regardless of the way in which the migration status was analysed (at least one parent migrant, only fathers migrant, only mothers migrant, etc.). Also, no significant differences were observed between the two groups regarding the acculturation experience assessed in our questionnaire (assimilation, rejection of the host country culture, melting pot).

Furthermore, no significant differences were found between the autism and control groups regarding migration-related stress levels when parents arrived in France, but also stress experienced years later related to more long-term consequences of migration such as social isolation.

Finally, no significant relationships were observed between the migration experience (cultural rituals, relationships with the 
Table 3 Bravais-Pearson correlations in children with autism spectrum disorder $(n=30)$ between Human Development Index (HDI)/ /Inequality-adjusted Human Development Index (IHDI) values of native countries and autism severity scores (only domains with significant results are presented with Pearson $r$ and $P$-values

\begin{tabular}{|c|c|c|c|c|}
\hline Scales & $\begin{array}{l}\text { CARS total } \\
\text { score }\end{array}$ & $\begin{array}{l}\text { CARS social } \\
\text { interaction }\end{array}$ & $\begin{array}{l}\text { ADOS social } \\
\text { interaction }\end{array}$ & $\begin{array}{l}\text { ADOS } \\
\text { play }\end{array}$ \\
\hline \multicolumn{5}{|l|}{$\begin{array}{l}\text { Father } \\
\mathrm{HDI}\end{array}$} \\
\hline$r$ & -0.40 & -0.36 & -0.33 & -0.31 \\
\hline$P$ & 0.03 & 0.05 & 0.08 & 0.10 \\
\hline$r$ & -0.41 & -0.37 & -0.32 & -0.32 \\
\hline$P$ & 0.03 & 0.05 & 0.09 & 0.10 \\
\hline \multicolumn{5}{|c|}{ Paternal grandmother } \\
\hline$r$ & -0.46 & -0.48 & -0.41 & -0.38 \\
\hline $\begin{array}{l}P \\
\mid \mathrm{HDI}\end{array}$ & 0.01 & 0.01 & 0.03 & 0.04 \\
\hline r & -0.46 & -0.49 & -0.41 & -0.39 \\
\hline P & 0.01 & 0.008 & 0.03 & 0.04 \\
\hline \multicolumn{5}{|c|}{$\begin{array}{l}\text { Paternal grandfather } \\
\mathrm{HDI}\end{array}$} \\
\hline$r$ & -0.46 & -0.48 & -0.42 & -0.38 \\
\hline$P$ & 0.01 & 0.009 & 0.03 & 0.04 \\
\hline IHDI & & & & \\
\hline r & -0.41 & -0.44 & -0.36 & -0.42 \\
\hline$P$ & 0.03 & 0.02 & 0.04 & 0.03 \\
\hline
\end{tabular}

native community, stress levels related to short- or long-term immigration effects, etc.) and the severity of autistic behavioural impairments assessed on the CARS, ADOS and ADI-R scales.

\section{Relationships between HDI/IHDI and autism}

Mean values of HDI/IHDI were significantly lower for the parents and grandparents in the ASD group, especially for the paternal grandparents, compared with the pathological non-ASD control group (Table 2). It is noteworthy that HDI/IHDI mean values were systematically lower in the ASD group compared with the control group.

In both groups, migrants had significantly lower HDI/IHDI mean values than non-migrants, showing that migrants come from countries with lower human developmental levels compared with France (in France, HDI $=0.897 / \mathrm{IHDI}=0.813$ ).

Focusing on migrant parents from the ASD and control groups, HDI/IHDI mean values remained systematically lower in the ASD group compared with the control group (it was not possible to test the significance of differences between the two groups because of small samples) and differed between the two groups with regard to human developmental level thresholds: in the migrant ASD group, parents came from countries where human developmental levels were 'low' based on IHDI values (or 'average' based on HDI values), whereas in the migrant control group, parents came from countries where human developmental levels were 'average' based on IHDI values (or 'high' based on HDI values).

Finally, HDI and IHDI values from the paternal line (father, paternal grandmother and grandfather) were significantly and negatively correlated with the overall score of autism severity (CARS Total score), especially with the severity of social interaction impairments assessed using the CARS as well as ADOS scales. The lower the HDI/IHDI values were, the more severe current autistic behavioural impairments were, particularly for social interaction impairments (Table 3).

\section{Discussion}

\section{Main finding}

The main finding of the study was the absence of significant difference between the ASD and control groups for migration (the migratory trip and postmigration experience), whereas HDI/IHDI values of native countries were significantly lower for parents and grandparents in the ASD group compared with the control group and were correlated with autism severity for the paternal line.

\section{Migration and autism}

Parents' and/or grandparents' migration did not discriminate the ASD group from the pathological non-ASD control group and was not associated with autism severity. These results are in line with Gillberg et al's study ${ }^{12}$ reporting an absence of significant relationship between parental migration and autism.

Given that our two studied groups shared verbal language impairments, potential relationships between migration and language disorders can be questioned. However, no relationship was found in the present study between parental migration and severity of verbal communication impairments in children with autism regardless of the autistic behavioural assessment used (CARS, ADOS or ADI-R). Furthermore, no significant difference was observed between the ASD and control subgroups of migrant parents regarding the language spoken to the child by parents at home (same language as school or other language). This result is in line with those of other studies suggesting no effects of bilingualism on autism development.

However, our qualitative results showed that some migrant mothers from the ASD group did not allow themselves to speak their mother tongue with their children (as in the Ijalba study ${ }^{30}$ ), whereas all migrant mothers from the control group spoke to their children in their mother tongue. These qualitative results suggest that a rupture with children's mother tongue more than bilingualism might be an environmental factor involved in ASD. The differences in language spoken to the child by the parents at home between the ASD and control migrant subgroups might also be related to the proximity between the mother tongue and the host tongue given that most of the native countries are French-speaking countries (70\%) in the ASD migrant subgroup and non-French-speaking countries $(60 \%)$ in the control migrant subgroup. Furthermore, differences in the language spoken at home between the ASD and control migrant subgroups could be related to the different ways of dealing with their premigratory experience, the family's will to integrate the host country, and the level of inter/intragroup conflict they have to face. Indirectly, these differences could be related more to premigratory factors (such as the breaking with the native 'old' country because of high levels of premigratory stress) than to migratory factors. Finally, the reluctance to use the mother tongue at home in the ASD group might reflect the need for migrant families to be integrated in the host country to the point of trying to erase major and essential differences of cultural identity such as language differences. This may lead to the opposite effect on the child with a stressful state of confusion and a reactional social withdrawal from the native country group (the family) and from the host country group (French people). Moreover, the reluctance to use the mother tongue at home in the ASD group, and therefore to preserve language specificities from the native country, might lead to problems of self-other differentiation. This is of particular interest considering that ASD can be viewed as a neurodevelopmental disorder with problems of self-other differentiation. ${ }^{31}$ However, it is 
noteworthy that these qualitative results were not supported by statistical analyses, and therefore further studies are required.

\section{Social adversity and autism}

HDI/IHDI values of native countries allow the ASD group to be differentiated from the pathological control group, whereas social adversity levels experienced in the host country (France in our study), measured by parental stress levels when arriving in France and years later, were not significantly different between migrant ASD and control groups and were not associated with autism severity. These results suggest that higher social adversity experienced in native but not host countries is associated with autism (HDI/IHDI values reflect, as previously indicated in the introduction, social adversity levels). The significant association found in the present study between HDI values and autism diagnosis is in line with Magnusson et al's study. ${ }^{7}$ Interestingly, several studies showing associations between migration and autism concerned native countries with low HDI values, even if HDI values were not specifically reported. ${ }^{6,13,16}$ In addition, relationships between low HDI levels and development of schizophrenia have been observed in migrant populations. $^{32}$

It is noteworthy that, as shown in Table 3, HDI/IHDI values from the paternal line (father, paternal grandmother and grandfather) were significantly and negatively correlated with autism severity (CARS Total score), particularly for social interaction impairments (CARS and ADOS). Furthermore, the strongest correlations were observed for paternal grandparents (the significance was also the highest for them when comparing the HDI/IHDI values in the ASD and control groups; Table 2). Given that half of paternal grandparents migrated without the father (father born in France) in the ASD group, these results suggest, in contrast to Keen et $\mathrm{al}^{6}{ }^{6}$ that even without parental migration, a risk of developing severe autistic impairments, notably social interaction impairments, exists if paternal grandparents have migrated.

How can we understand this ASD risk passed down through the paternal line, especially through paternal grandparents? This transgenerational transmission could come from family history transmission and/or genetic heritage transmission involving epigenetic mechanisms.

Indeed, trauma and early-life adversity can produce a lasting epigenetic memory that may affect the behaviour and mental health status of the next two or three generations. ${ }^{3-36}$ Interestingly, some authors stated the hypothesis that epigenetic changes in migratory communities might increase ASD risk. ${ }^{8}$ Our study questions epigenetic changes related to social adversity experienced in native countries by parents and/or grandparents. Social adversity may lead to major premigration stress, psychological (perceived stress) as well as biological stress (biological stress responses), independently of potential trauma associated with the migratory trip and postmigration experience; this premigration stress would in turn modify gene expression through epigenetic mechanisms. Epigenetic changes as a result of social adversity-related stress in native countries could be transmitted to future generations, particularly through the paternal line as suggested by epigenetic studies. ${ }^{5,34-38}$

Furthermore, as indicated in the introduction, migration can be viewed as a 'physical act' but also as a 'psychological act' passed down to children and involving descendants. Family history in native countries related to premigration social adversity might be transmitted to descendants through the paternal line, especially by paternal grandparents. Social adversity is associated with difficulties to get a social position and take place in the social environment or social group with possible consequences on social interactions. According to several authors, ${ }^{39}$ social position is most of the time occupied by men compared with women, especially in patriarchal societies (i.e. societies governed/run by men), and socioeconomic precarity with its relevant social representation is usually transmitted through the paternal line. It is noteworthy that for the ASD group in the present study, all the mothers' levels of education were lower or equal to the fathers' ones, and all the native countries for migrant paternal grandparents and/or fathers concerned patriarchal societies. Social position has been found to be the only variable, among other social variables such as marital or parental status, with a substantially different effect in male versus female rates of trauma (low social position was associated with higher rates of trauma in men than in women). ${ }^{39}$ This suggests that social adversity experienced in native countries, which involves major difficulties or even the impossibility to gain social status and finding one's place in the social environment, might be more traumatic for men than women with a risk of transgenerational transmission of this trauma. In line with this idea, autism (a disorder with major social interaction impairments and male prevalence), could be viewed as a social disorder with difficulties to find one's place in the social environment.

Finally, it can be hypothesised that autism might reflect, in a context of family migration, the psychological and/or biological consequences of social adversity experienced in native countries especially by fathers and paternal grandparents. It is noteworthy that Abraham \& Torok, ${ }^{40}$ based on their observation and interpretation of qualitative results from clinical case studies, described the transgenerational transmission of trauma with different steps (first generation: the unspeakable situation, second generation: the unnameable situation, third generation: the unthinkable situation), the third generation expressing the most apparent disorders. This opens up new perspectives for potential therapeutic benefits and prevention of ASD in migrant families (at least for decreasing social interaction impairments) by working on verbal expression, narration and representation of social adversity-related stress experienced in native countries, especially by the paternal line.

\section{Importance of the premigration experience}

Concerning the association between autism and migration reported by prior studies, it may not be migration but rather coming from countries with low HDI/IHDI that could be a factor of vulnerability for autism. Therefore, the risk of autism would be related more to social adversity experienced in native countries by parents and grandparents before migration (reflected by HDI/IHDI values) than migration itself. Our results highlight the importance of the premigration experience. Migration needs to be integrated into the framework of a trajectory that cannot be limited to the migratory trip and the postmigration experience but includes also the premigration experience. This trajectory results in biological responses (including genetic expression) and psychological responses. As some authors have developed the 'migration theory of autism', we propose the 'premigration theory of autism' stating that social adversity-related stress experienced in native countries might be associated with autism.

\section{Study limitations}

Some limitations of the current study should be acknowledged. Sample sizes were small and the study is therefore exploratory. Furthermore, in the present study only two families migrated during the perinatal period. Given that higher migration-related stress vulnerability has been observed during the perinatal period (more precisely, during the year before the child's birth according to Magnusson et $\mathrm{al}^{7}$ ), effects of the migratory trip and early postmigratory experience on the development of ASD might be underestimated in this study. Finally, generalisation of the findings require 
future studies extended to other cultural contexts involving additional native countries from which migrants come and different host countries than France.

\section{Implications}

In conclusion, the findings show that premigration social adversity but not migration (migratory trip and postmigration experience) is significantly associated with autism. This is, to our knowledge, the first study on migration in autism to compare ASD and pathological non-ASD control groups in order to test the specificity of the results in autism. However, we cannot rule out possible effects of migration-related stress when the migration experience occurs during pregnancy, as well as possible postmigration effects related to the reluctance to use native language at home in the ASD group. Furthermore, our results suggest that premigration-related stress, such as social adversity in native countries experienced by parents and grandparents (especially paternal grandparents), reflected by low HDI/IHDI values, might play a role in the development of ASD for the descendants.

The findings underline the importance of considering HDI/ IHDI values of native countries, especially paternal grandparents' ones, when studying relationships between migration and autism in future research. Finally, a premigration theory of autism can be proposed stating that social adversity-related stress experienced in native countries might be a traumatic experience and factor of vulnerability for ASD. Premigration stress effects would be transmitted over several generations through paternal lineage (particularly by paternal grandparents) with genetic heritage (involving epigenetic mechanisms) and/or family heritage (involving narration and filiation).

\footnotetext{
Natacha Augereau, MD, Pôle Hospitalo-Universitaire de Psychiatrie de l'Enfant et de I'Adolescent de Rennes (PHUPEA), Centre Hospitalier Guillaume Régnier (CHGR) and Université de Rennes 1, France; Ines Lagdas, MD, School of Medicine of Rabat, University of Rabat, Marrocco; and PHUPEA, CHGR and Université de Rennes 1, France: Solenn Kermarrec (D), MD, PhD, PHUPEA, CHGR and Université de Rennes 1, France; Ludovic Gicquel, MD, PhD, Pôle Hospitalo-Universitaire de Psychiatrie de l'Enfant et de I'Adolescent, Centre Hospitalier Henri Laborit and Université de Poitiers, Unité de Recherche Clinique, CAPS, Poitiers, France; Virginie Martin, Pôle HospitaloUniversitaire de Psychiatrie de l'Enfant et de l'Adolescent, Centre Hospitalier Henri Laborit; and Université de Poitiers, Unité de Recherche Clinique, CAPS, France; Jean Xavier, MD, PhD, Centre Hospitalier Spécialisé Henri Laborit, Poitiers; and CNRS UMR 7295 Centre de Recherches sur la Cognition et l'Apprentissage, Poitiers, France; David Cohen, MD, PhD, Department of Child and Adolescent Psychiatry, AP-HP, GH Pitié-Salpétrière, CNRS FRE 2987, University Pierre and Marie Curie, France: Michel Bouvet, MD, Service Hospitalo-Universitaire de Psychiatrie de l'Enfant et de I'Adolescent de Reims, Pôle Femme-Parents-Enfant, France; Anne-Catherine Rolland MD, PhD, Service Hospitalo-Universitaire de Psychiatrie de l'Enfant et de I'Adolescent de Reims, Pôle Femme-Parents-Enfant, France; Sylvie Tordjman (D, MD, PhD, Pôle Hospitalo-Universitaire de Psychiatrie de l'Enfant et de I'Adolescent (PHUPEA), Centre Hospitalier Guillaume Régnier (CHGR) and Université de Rennes 1; and Integrative Neuroscience and Cognition Center (INCC), CNRS UMR 8002 and Université de Paris, France

Correspondence: Sylvie Tordjman. Email: s.tordjman2@gmail.com

First received 12 Apr 2020, final revision 5 Jun 2020, accepted 10 Jun 2020
}

\section{Data availability}

The structure of the data-set and the coding specification are available from the authors on request.

\section{Acknowledgements}

We thank the University of Rennes 1 for their financial support, particularly the School of Medicine of Rennes who supported the research project presented by S.T.

\section{Author contributions}

S.T. conceived and designed the study. N.A., S.T. and I.L. conceived and designed the migrant status questionnaire and N.A. administered this questionnaire during semi-structured parental interviews for all participants. S.T., S.K., L.G., V.M., J.X., D.C., A.-C.R. and M.B. recruited the children in the ASD group, and N.A. and I.L. recruited the children in the control group. S.K., J.X. and
V.M. participated in the behavioural assessments of autism severity. S.T. and N.A. performed the data analysis. N.A. and S.T. wrote the manuscript, and all authors commented on the manuscript and revised the article.

\section{Funding}

This work was supported by the University of Rennes 1 (COREQ research grant).

\section{Declaration of interest}

None.

ICMJE forms are in the supplementary material, available online at https://doi.org/10.1192/ bjo.2020.56.

\section{References}

1 Tordjman S, Cohen D, Coulon N, Anderson GM, Botbol M, Canitano R, et al. Reframing autism as a behavioural syndrome and not a specific mental disorder: implications of genetic and phenotypic heterogeneity. Neurosci Biobehav Rev 2018; 89: 132-50.

2 Gardener H, Spiegelman D. Buka SL. prenatal risk factors for autism: comprehensive meta-analysis. Br J Psychiatry 2009; 195: 7-14.

3 Rai D, Lewis G, Lundberg M, Araya R, Svensson A, Dalman C, et al. Parental socioeconomic status and risk of offspring autism spectrum disorders in a Swedish population-based study. J Am Acad Child Adolesc Psychiatry 2012; 51: 467-76.

4 Delobel-Ayoub M, Ehlinger V, Klapouszczak D, Maffre T, Raynaud JP, Delpierre $\mathrm{C}$, et al. Socioeconomic disparities and prevalence of autism spectrum disorders and intellectual disability. Plos One 2015; 10: e0141964.

5 Tordjman S, Somogyi E, Coulon N, Kermarrec S, Cohen D, Bronsard G, et al. Gene $X$ environment interactions in autism spectrum disorders: role of epigenetic mechanisms. Front Psychiatry 2014; 5: 1-17

6 Keen DV, Reid FD, Arnone D. Autism, ethnicity and maternal immigration. Br J Psychiatry 2010; 196: 274-81.

7 Magnusson C, Rai D, Goodman A, Lundberg M, Idring S, Svensson A, et al. Migration and autism spectrum disorder: population-based study. $\mathrm{Br} J$ Psychiatry 2012; 201: 109-15.

8 Crafa D, Warfa N. Maternal migration and autism risk: systematic analysis. Int Rev Psychiatry 2015; 27: 64-71.

9 Wing L. Childhood autism and social class: a question of selection. $\mathrm{Br} J$ Psychiatry 1980; 137: 410-17.

10 Gillberg C, Steffenburg S, Börjesson B, Andersson L. Infantile autism in children of immigrant parents. A population-based study from Goteborg, Sweden. $\mathrm{Br} J$ Psychiatry 1987; 150: 856-8.

11 Gillberg C, Schaumann H, Gillberg IC. Autism in immigrants: children born in Sweden to mothers born in Uganda. J Intellect Disabil Res 1995; 39: 141-4.

12 Gillberg IC, Gillberg C. Autism in immigrants: a population-based study from Swedish rural and urban areas. J Intellect Disabil Res 1996; 40: 24-31.

13 Lauritsen MB, Pedersen CB, Mortensen PB. Effects of familial risk factors and place of birth on the risk of autism: a nationwide register-based study. J Child Psychol Psychiatry 2005; 46: 963-71.

14 Barnevik-Olsson M, Gillberg C, Fernell E. Prevalence of autism in children of Somali origin living in Stockholm: brief report of an at-risk population. Dev Med Child Neurol 2010; 52: 1167-8.

15 Schieve LA, Boulet SL, Blumberg SJ, Kogan MD, Yeargin-Allsopp M, Boyle CA et al. Association between parental nativity and autism spectrum disorder among US-born non-Hispanic white and Hispanic children, 2007 national survey of children's health. Disabil Health J 2012; 5: 18-25.

16 Becerra TA, von Ehrenstein OS, Heck JE, Olsen J, Arah OA, Jeste SS, et al. Autism spectrum disorders and race, ethnicity and nativity: a population-based study. Pediatrics 2014; 134: 63-71.

17 United National Development Programme. Human Development Index. United National Development Programme, no date (http://hdr.undp.org/en/content/ human-development-index-hdi).

18 American Psychiatric Association. Diagnostic and Statistical Manual of Mental Disorders, 5th edn (DSM-5). American Psychiatric Association, 2013.

19 World Health Organization. The ICD-10 Classification of Mental and Behavioural Disorders: Clinical descriptions and diagnostic guidelines. WHO, 1992

20 Misès $R$, Botbol $M$, Bursztejn $C$, Coinçon $Y$, Durand $B$, Garrabé J, et al. Classification Française des Troubles Mentaux de l'Enfant et de l'Adolescent. Ehesp, 2012

21 Lord C, Rutter M, Le Couteur A. Autism Diagnostic Interview-Revised: a revised version of a diagnostic interview for caregivers of individuals with possible pervasive developmental disorders. J Autism Dev Disord 1994; 24: 659-85. 
22 Lord C, Risi S, Lambrecht L, Cook EH Jr, Leventhal BL, DiLavore PC, et al. The Autism Diagnostic Observation Schedule-generic: a standard measure of social and communication deficits associated with the spectrum of autism. J Autism Dev Disord 2000; 30: 205-23.

23 Risi S, Lord C, Gotham K, Corsello C, Chrysler C, Szatmari P, et al. Combining information from multiple sources in the diagnosis of autism spectrum disorders. J Am Acad Child Adolesc Psychiatry 2006; 45: 1094-103.

24 Editions du Centre de Psychologie Appliquée. Manual for the Raven's Color Progressive Matrices (CPM). Editions du Centre de Psychologie Appliquée (ECPA), 2016.

25 Dawson $\mathrm{M}$, Soulières I, Gernsbacher MA, Mottron L. The level and nature of autistic intelligence. Psychol Sci 2007; 18: 657-62.

26 Mottron L. Changing perceptions: the power of autism. Nature 2011; 479 33-35.

27 Herskowits M. Acculturation, the Study of the Culture Contact. J.J. Augustin, 1938.

28 Cohen J, Cohen P. Applied Multiple/Correlation Analysis for the Behavioural Sciences (2nd edn). Erlbaum, 1983.

29 Strauss J, Corbin C. Grounded Theory in Practice. Sage, 1997.

30 ljalba E. Hispanic immigrant mothers of young children with autism spectrum disorders: how do they understand and cope with autism? Am J Speech Lang Pathol 2016; 25: 200-13.

31 Tordjman S, Celume MP, Denis L, Motillon T, Keromnes G. Reframing schizophrenia and autism as bodily self-consciousness disorders leading to a deficit of theory of mind and empathy with social communication impairments. Neurosci Biobehav Rev 2019; 103: 401-13.

32 Cantor-Graae E, Selten JP. Schizophrenia and migration, a meta-analysis and review. Am J Psychiatry 2005; 162: 12-24.
33 Cao-Lei L, de Rooij SR, King S, Matthews SG, Metz GAS, Roseboom TJ, et al Prenatal stress and epigenetics. Neurosci Biobehav Rev [Epub ahead of print] 18 May 2017. Available from: https://doi.org/10.1016/j.neubiorev.2017.05.016

34 Gapp K, Jawaid A, Sarkies P, Bohacek J, Pelczar P, Prados J, et al. Implication of sperm RNAs in transgenerational inheritance of the effects of early trauma in mice. Nat Neurosci 2014; 17: 667-9.

35 Morgan CP, Bale TL. Early prenatal stress epigenetically programs dysmasculinization in second-generation offspring via the paternal lineage. J Neurosci 2011: 31: 11748-55.

36 Jones BC, Mormede P. Neurobehavioral Genetics: Methods and Applications. CRC Press, 2002

37 Franklin TB, Russig $\mathrm{H}$, Weiss IC, Gräff J, Linder N, Michalon A, et al. Epigenetic transmission of the impact of early stress across generation. Biol Psychiatry 2010; 68: 408-15.

38 Morgan $\mathrm{CP}$, Chan JC, Bale TL. Driving the next generation: paternal lifetime experiences transmitted via extracellular vesicles and their small RNA cargo. Biol Psychiatry 2019; 85: 164-71.

39 Gijsbers van Wiik C, Kolk AM, Van Den Bosch W, Van Den Hoogen H. Male and female health problems in general pratice: the differential impact of social position and social roles. Soc Sci Med 1995; 40: 597-611.

40 Abraham N, Torok M. The Wolf Man's Magic Word: A Cryptonymy. University of Minnesota Press, 2005 